\title{
Fragmentation and partitioning of the Golgi apparatus during mitosis in HeLa cells
}

\author{
John M.Lucocq and Graham Warren \\ Department of Biochemistry, University of Dundee, Dundee DD1 4HN, \\ UK \\ Communicated by G. Warren
}

Osmium impregnation was used to determine the number of Golgi apparatus in both interphase and mitotic HeLa cells. The number was found to increase substantially during mitosis to the point where random partitioning alone would explain the nearly equal numbers found in each daughter cell. Key words: Golgi/mitosis/osmium

\section{Introduction}

By examination of thick sections using high-voltage electron microscopy Rambourg et al. $(1974,1979,1981)$ and others (Novikoff $e t$ al., 1971) concluded that animal cells contain but a single copy of the Golgi apparatus. It appears that animal cells cannot synthesize this organelle de novo (Wilson, 1925; Zorn et al., 1979) so it must be divided when the cell divides. The mechanism is unknown but appears to involve extensive breakdown (Maul and Brinkley, 1970; Zeligs and Wollman, 1979) yielding many Golgi fragments. These fragments have been observed by light microscopy using both cytochemical (Ludford, 1924; Wilson, 1925) and immunofluorescence (Burke et al., 1982; Hiller and Weber, 1982) techniques and more recently by electron microcopy using a high-resolution immunocytochemical technique (Lucocq et al., 1987). Random dispersal of these fragments followed by division into two daughters of equal size would ensure that each receives nearly equal numbers of Golgi fragments. They would then re-form the interphase Golgi apparatus in the centrosomal region of each daughter cell (see Warren, 1985).

There are two assumptions implicit in the proposed mechanism which are questionable when studying cultured cells such as HeLa cells. The first is that interphase HeLa cells contain a single copy of the Golgi apparatus. The work which led to the idea of a single copy was carried out on highly differentiated cells which do not generally divide so they should not need to divide their Golgi apparatus. Results from such cells cannot be extrapolated to HeLa cells which divide frequently and have need of a Golgi division mechanism. At first sight immunofluorescence studies do suggest that HeLa cells contain a single Golgi copy (Roth and Berger, 1982) but the technique has low resolution and cannot distinguish between a single copy and multiple Golgi stacks grouped so closely together in the centrosomal region of the cell that they appear as a single copy. If there are in fact multiple Golgi stacks then there would be no need of a fragmentation mechanism since, at the onset of mitosis, these multiple stacks would simply disperse throughout the mitotic cell cytoplasm thereby ensuring division of the Golgi apparatus.

The second assumption is that sufficient fragments are produced to allow equal partitioning by a random process (see Birky, 1983). If, for example, only two fragments were produced then there would be a significant chance that one of the daughters would receive both fragments leaving the other with none. This daughter would then die, so a counting mechanism would be needed in this instance, If however, hundreds of fragments were produced, then random partitioning alone should ensure nearly equal numbers in each daughter cell.

To test these two assumptions we have counted the number of Golgi apparatus and Golgi fragments in interphase and mitotic HeLa cells respectively. Thick sections offer the best means of counting organelles which pervade large areas of cell cytoplasm and prolonged osmication makes it possible to visualise the cis cisterna which is a representative part of the Golgi apparatus. The results we obtained support the idea of fragmentation and random partitioning.

\section{Results}

\section{Osmium staining of the interphase Golgi apparatus}

Impregnation with osmium has classically been used to stain the cis Golgi cisterna in a variety of tissue cells (see for example Friend and Murray, 1965) but to our knowledge there is no published data on the results of osmium impregnation of cultured cells. Using HeLa cells and prolonged impregnation according to the method of Locke and Huie (1983), osmium was consistently found to stain one cisterna on one side of the interphase Golgi stack (Figure 1a and b). Very occasionally, two cisternae on one side appeared stained. All other cisternae of the Golgi stack were negative. The stained cisterna was interrupted in transverse sections of the stack (Figure 1a and b) whereas suitable oblique sections showed the cisterna to be fenestrated (Figure 1c). In separate experiments, the trans Golgi marker, TPPase, was found to stain the largely uninterrupted cisterna on the opposite side of the stack to the interrupted (fenestrated) cisterna. This argues strongly that osmium is a marker for the cis Golgi cisterna(e) in HeLa cells as it is in other tissue cells (e.g. Friend and Murray, 1965) and can be used as a representative cisternal marker in the studies which follow.

The rough endoplasmic reticulum (RER) was also stained by osmium but the staining was variable from cell to cell; in some cells it was intense and in others it was absent (Friend, 1969). Mitotic cells had intense staining of the RER more frequently than interphase ones. Endoplasmic reticulum (ER) staining was more granular (see for example Figure $4 \mathrm{~b}$ and $\mathrm{c}$ ) than that of the cis cisterna and could be differentiated from it when looking at the sections in the electron microscope. The only other identifiable organelles that were clearly stained by osmium were the multivesicular bodies (see, for example, Figure 5).

\section{Number of interphase Golgi apparatus}

In sections of interphase cells 1-2 $\mu$ m thick the cis Golgi cisterna comprised an extensive, fenestrated, ribbon-like structure (Figure 2c) in a restricted juxtanuclear position (Figure 2a). As one follows the ribbon, it twists, turns and branches, the latter interconnecting so that the resultant form, in many cells, is domelike with base the folded up into the body of the dome (Figure 

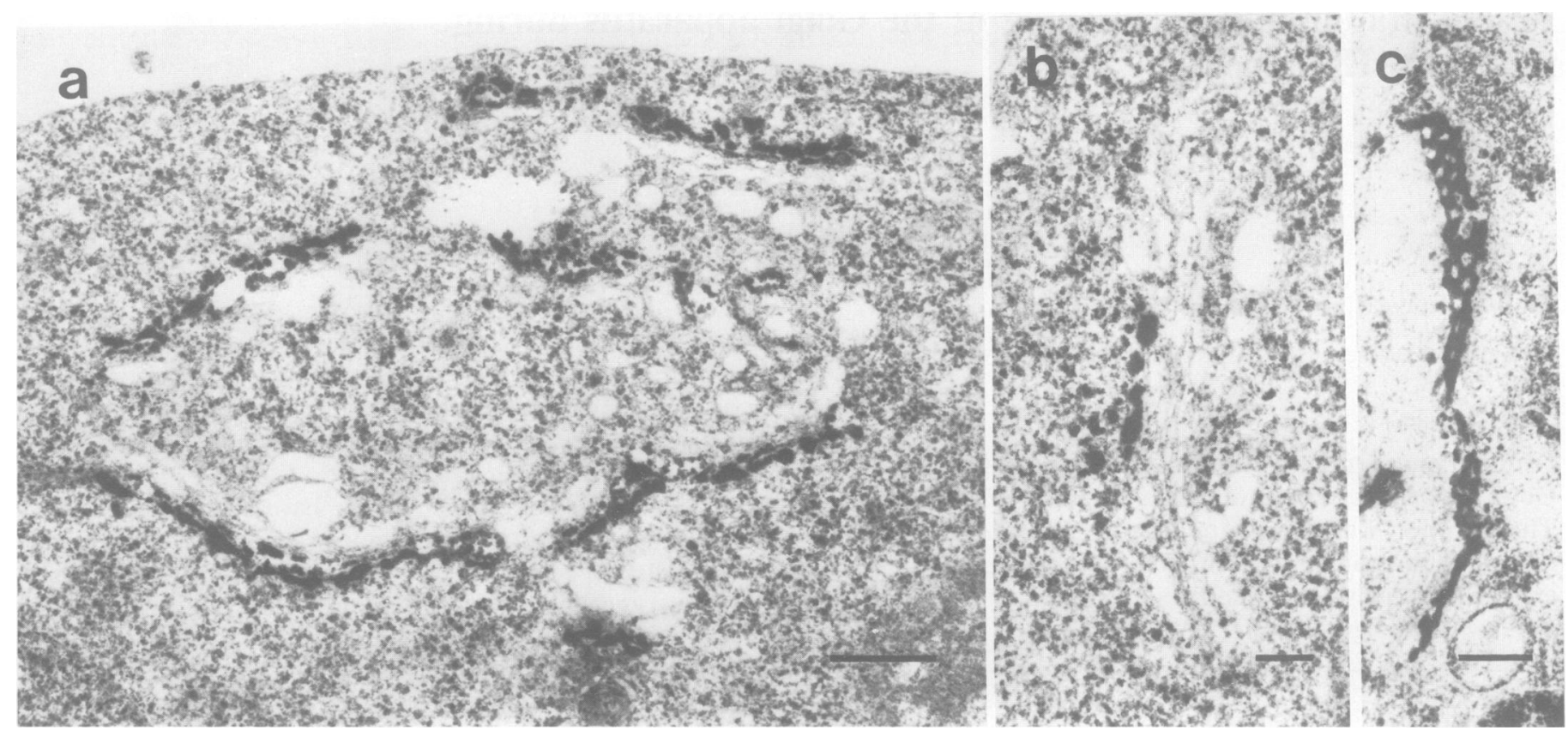

Fig. 1. Osmium staining in thin section of interphase HeLa cells. In transverse sections of the Golgi stack (a and b) staining is limited to one and at most two cisternae on one side. In oblique sections (c) the fenestrated nature of the cis cisterna is apparent. Bars $0.2 \mu \mathrm{m}$.

$2 b)$. The base is often apposed to the nuclear envelope (Figure $2 b$ and $d)$.

Counting the number of Golgi apparatus in thick sections poses certain difficulties. The thicker the section, the better the overview, but superimposition becomes more likely so that discrete structures can appear continuous. This difficulty is lessened by making the sections thinner but it then becomes impossible to decide whether a continuous structure actually bridges the gap between sections. The thickness is therefore a compromise, and for our purposes the monolayer was sectioned en face from the bottom to give three 1.5- $\mu \mathrm{m}$-thick sections. Each of these three sections was examined and the number of discrete Golgi profiles in each cell profile was counted.

The results are presented in Table $I$. The mean number in each cell profile in each of the three sections varies between two and three. The sum of these means is 7.7 so that the expected number of Golgi apparatus in a HeLa cell is eight. This is an overestimate for several reasons. First, we have assumed that none of the Golgi profiles counted bridge sections. Second, unstained cell profiles comprised $36 \%$ of the total cell profiles (Figure 3 ) yet were not included, in case the original cell as a whole had not been stained by osmium. Third, this same figure shows that cell profiles containing three or more Golgi profiles were in the minority (39\% of those used for calculation of the mean) but had a disproportionate effect on the mean value. Most of these profiles represented single Golgi that had been sectioned at the periphery to give multiple profiles. In fact most of the cell profiles contained only one or two Golgi profiles $(61 \%$ of those used for calculation of the mean).

Osmium staining of mitotic Golgi clusters

We recently described a major fragment of the Golgi apparatus in mitotic HeLa cells which we termed the Golgi cluster (Lucocq et al., 1987). Clusters each comprise a group of large, electronlucent vesicles up to $250 \mathrm{~nm}$ in diameter, and a group of smaller, vesiculo-tubular structures with a cross-sectional diameter of $\sim 50 \mathrm{~nm}$. The trans Golgi markers TPPase and galac- tosyltransferase were found in some of the smaller vesiculotubular structures and to a lesser extent in some of the large vesicles. Clusters are bounded by elements of the RER, sometimes on all sides. They are easily identified by their morphology and can be found in HeLa cells impregnated with osmium (Figure 4). Osmium consistently stained the group of small vesicles next to the RER (Figures 4b, $c$ and 5c). During telophase some of these stained vesicles appear fused and in the early stages of reforming a cisterna in the position of the cis cisterna (Figure 6), i.e. on one side of the Golgi stack. This argues strongly that the vesicles stained by osmium in the cluster were derived from the interphase cis cisterna.

As already noted, osmium frequently stained the ER and this revealed projections from the ER into the cluster (Figures 4a, e and 5a, c) which had all the characteristics of the transitional element buds found in interphase HeLa cells (unpublished data) and described by other workers for other cell types (see Palade, 1975). 'Buds' [the word is placed within quotation marks because transport from the ER to the Golgi is inhibited during mitosis (Featherstone et al., 1985) and it is likely that these buds are not active] were present in five out of eight clusters in metaphase cells which were serially sectioned in their entirety. In some telophase cells as many as 10 'buds' were seen in a single section of a cluster. In consequence we consider the possession of associated 'budding' profiles to be a characteristic property of clusters. This, together with the osmium staining of cis-derived cisternae has allowed us to identify clusters smaller than those observed previously. At least some of these smaller clusters were also found to contain the trans Golgi marker TPPase (unpublished results).

\section{Number of mitotic Golgi clusters}

Preliminary experiments using thick sections showed that were many discrete Golgi clusters in mitotic cells. Figures 5 and 7 show that most of the clusters were peripheral though some were found on the nuclear envelope (Figure 7). Unfortunately the smaller the cluster the more difficult it was to see, so serial thin 

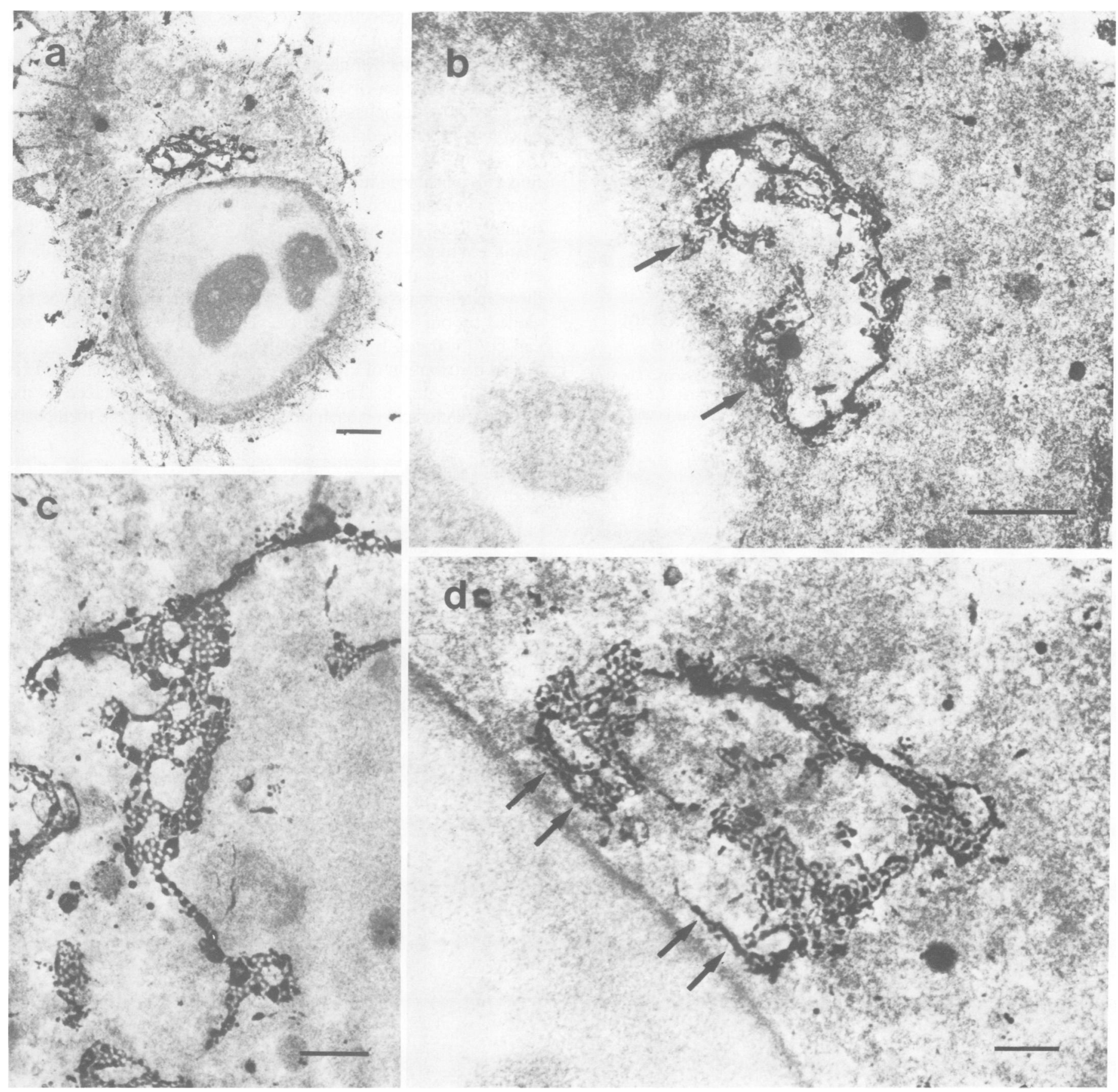

Fig. 2. Osmium staining in thick $(1.5 \mu \mathrm{m})$ sections of interphase HeLa cells. The cis Golgi cisterna appears as an inter-connected, fenestrated ribbon (c), often in the shape of a dome (b,d), and mostly situated in a juxtanuclear region (a). The base of the dome is apposed to the nuclear envelope (arrows in $\mathbf{b}$ and $\mathbf{d}$ ). Bars $2 \mu \mathrm{m}$ (a and b), $1 \mu \mathrm{m}$ (c and d).

sections of mitotic cells were cut in order to count accurately the number of clusters in each cell. On average, 200 sections were made and a total of seven cells were examined, three in metaphase and four in telophase. Of the latter, cytokinesis was incomplete in two and these are termed mid-telophase (one had an incomplete nuclear envelope); cytokinesis and the nuclear envelope were complete in the other two and these were termed late-telophase. A cluster was defined as either a stained transitional element and a closely associated stained vesicle or vesicles (e.g. Figure 4a and e), or at least three grouped osmium-stained vesicles closely associated with ER (Figure 4c). The latter identi-
Table I. Number of Golgi apparatus in interphase HeLa cells

\begin{tabular}{lll}
\hline Section $^{\mathrm{a}}$ & $\begin{array}{l}\text { Number of cell } \\
\text { profiles counted }^{\mathrm{b}}\end{array}$ & $\begin{array}{l}\text { Mean number of } \\
\text { discrete Golgi profiles }\end{array}$ \\
\hline 1 Bottom & 31 & 2.1 \\
2 Middle & 52 & 2.6 \\
3 Top & 45 & 3.0 \\
\hline
\end{tabular}

${ }^{a}$ The monolayer was sectioned en face from the bottom and each section was $1.5 \mu \mathrm{m}$ in thickness.

bOnly cell profiles containing osmium-stained Golgi were counted. 


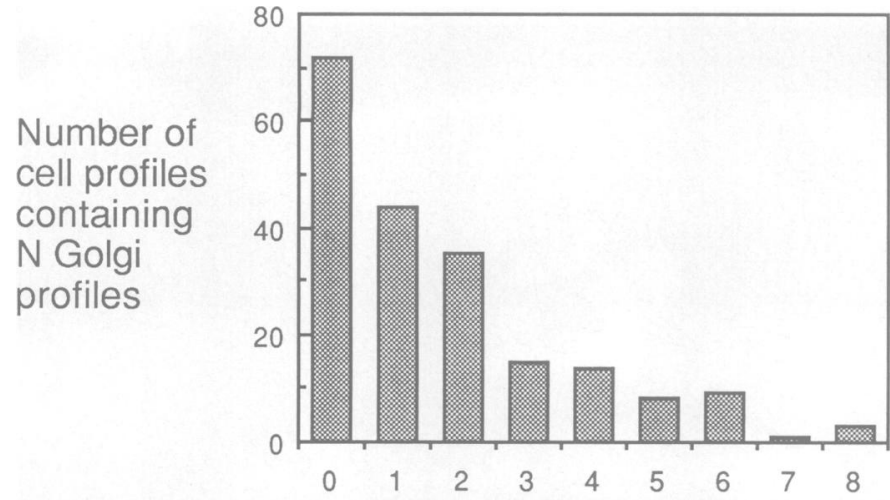

Number $(\mathrm{N})$ of discrete Golgi profiles in each cell profile

Fig. 3. Distribution of discrete Golgi profiles in the thick sections. The monolayer was sectioned en face from the bottom to give three $1.5-\mu \mathrm{m}$-thick sections. The number of Golgi profiles in each cell profile was counted and the data from each of the three sections were pooled. fied clusters at the cell periphery which had fewer transitional elements because of oblique sectioning.

The total number of clusters is presented in Table II. Assuming the distribution of clusters in the mid-telophase cells does not change as telophase progresses, then the mean number of clusters in each telophase daughter (both mid and late) is 94 (62-126, 95\% confidence limits). Thus, we would expect to find 188 clusters in a telophase cell. In contrast, the number of clusters in a metaphase cell was 146 (56-235, 95\% confidence limits). This difference is not however, significant by the Mann - Whitney (1947) $U$-test $(P=0.114)$ and may be explained by the fact that clusters in metaphase cells are smaller than those in telophase and are either missed during counting or excluded by our selection criteria. The difference in cluster size can be illustrated by comparing Figures $4 \mathrm{a}$ and $5 \mathrm{a}$.

The distribution of clusters in each half of the mitotic cells is shown in Figure 8. The metaphase distribution is taken as the number of clusters on each side of a line bisecting the metaphase

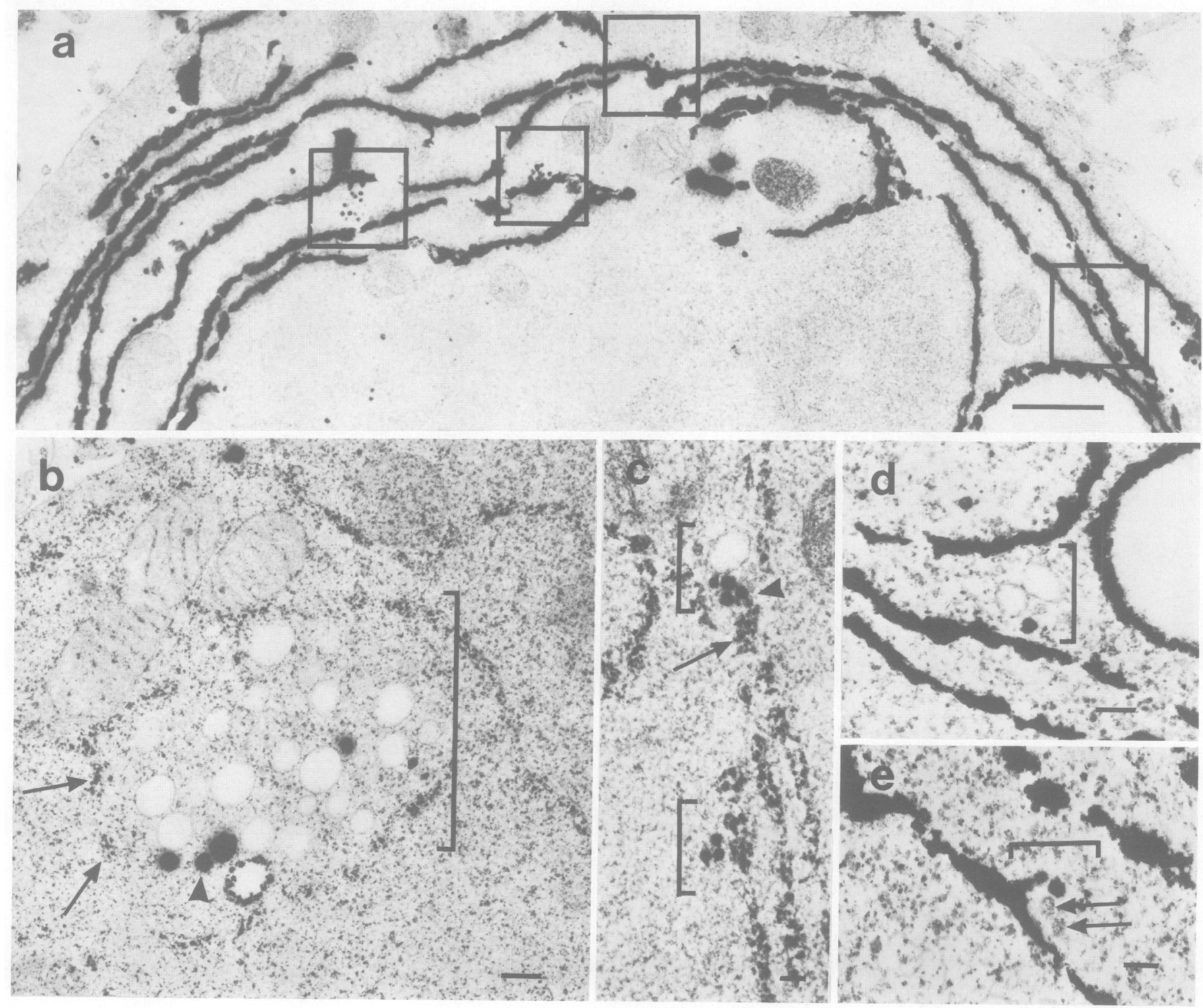

Fig. 4. Golgi clusters in thin sections of metaphase HeLa cells. (a) Identifiable Golgi clusters (boxed) are found in the periphery of this metaphase cell. In both large (b) and small (c,d and e) clusters (bracketed), osmium stains some (but not all) of the larger vesicles (arrowhead in b) and the smaller vesiculotubular structures (arrowhead pointing to group of four in c). A transitional element 'bud' (e) protrudes into the cluster of three vesicles, two of which (arrows) are unstained. Note the granular ER staining in $\mathbf{b}$ and $\mathbf{c}$ (arrows). The cluster in $\mathbf{d}$ contained three vesicles, but since only one was stained it was excluded from our quantitation. Bars $1 \mu \mathrm{m}(\mathbf{a}), 0.1 \mu \mathrm{m}(\mathbf{b}-\mathbf{e})$. 


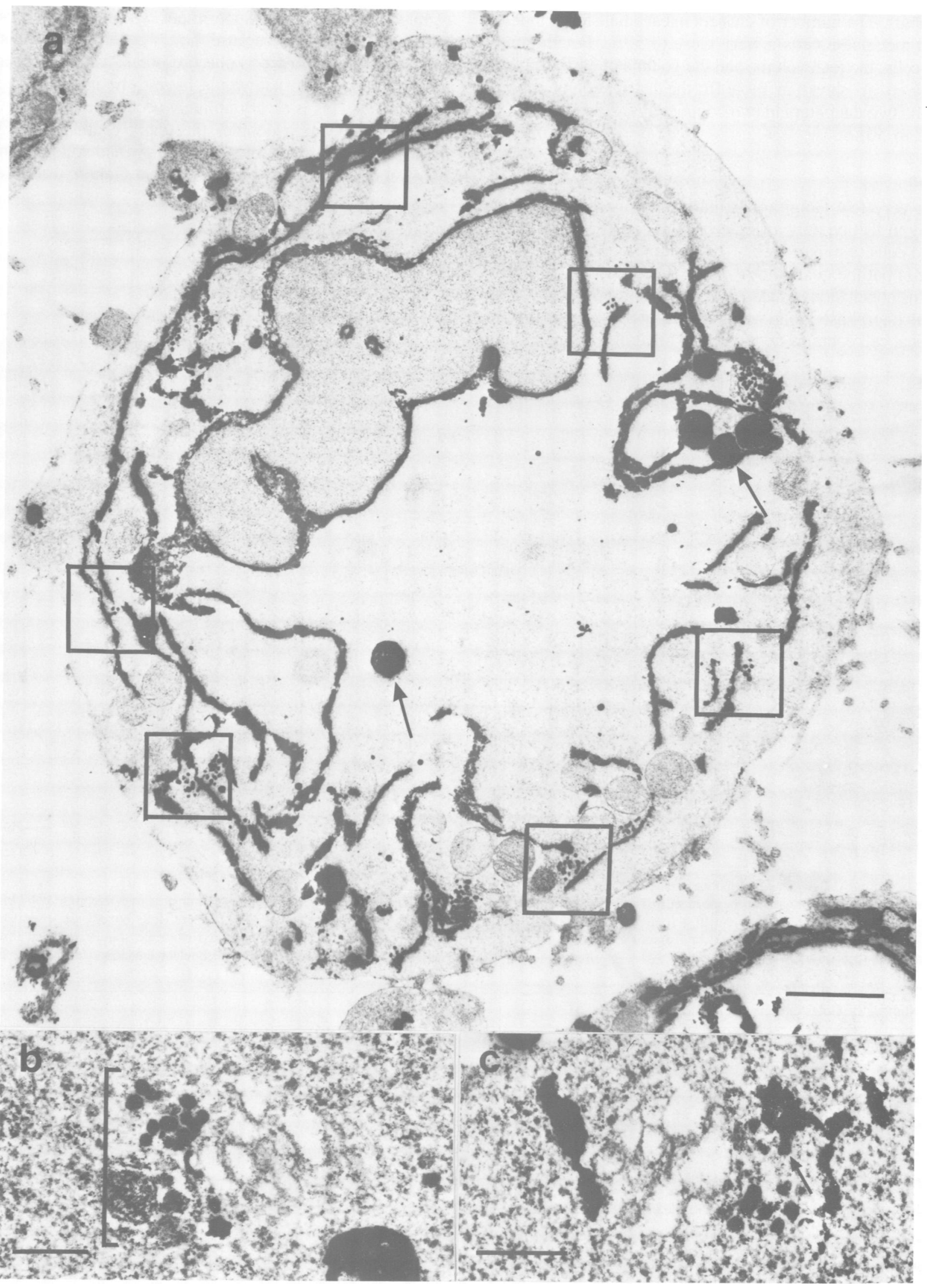

Fig. 5. Golgi clusters in a thin section of a late-telophase cell. Golgi clusters (some boxed in a) are dispersed but appear larger than in metaphase (cf. Figure 4a). Most contain 'budding' profiles of transitional elements. When the ER is unstained (b) a group of osmium-stained vesicles occur in one region of the cluster (bracketed). When the ER is stained (c) such stained vesicles are seen to be near the transitional element region (arrow pointing to 'bud'). Arrows in (a) point to multivesicular bodies also stained with osmium. Bar $2 \mu \mathrm{m}$ (a), $0.2 \mu \mathrm{m}$ (b and c). 
chromosomes. The number of clusters in each half for both telophase and metaphase cells is very close to $50 \%$. For the midtelophase cells, the total volume and the volume of each daughter was measured. As shown in Table III, the distribution of volume between the two daughters in two completely different cells was also close to $50 \%$.

\section{Discussion}

There are very few Golgi apparatus in interphase HeLa cells. There may in fact be only a single copy as found in certain differentiated cells (Novikoff et al., 1971; Rambourg et al., 1974, $1979,1981)$ but the quantitative method used does not allow us to draw this conclusion. Instead we can set an upper limit to the number of interphase Golgi apparatus in HeLa cells and state that a typical cell contains no more than eight discrete apparatus

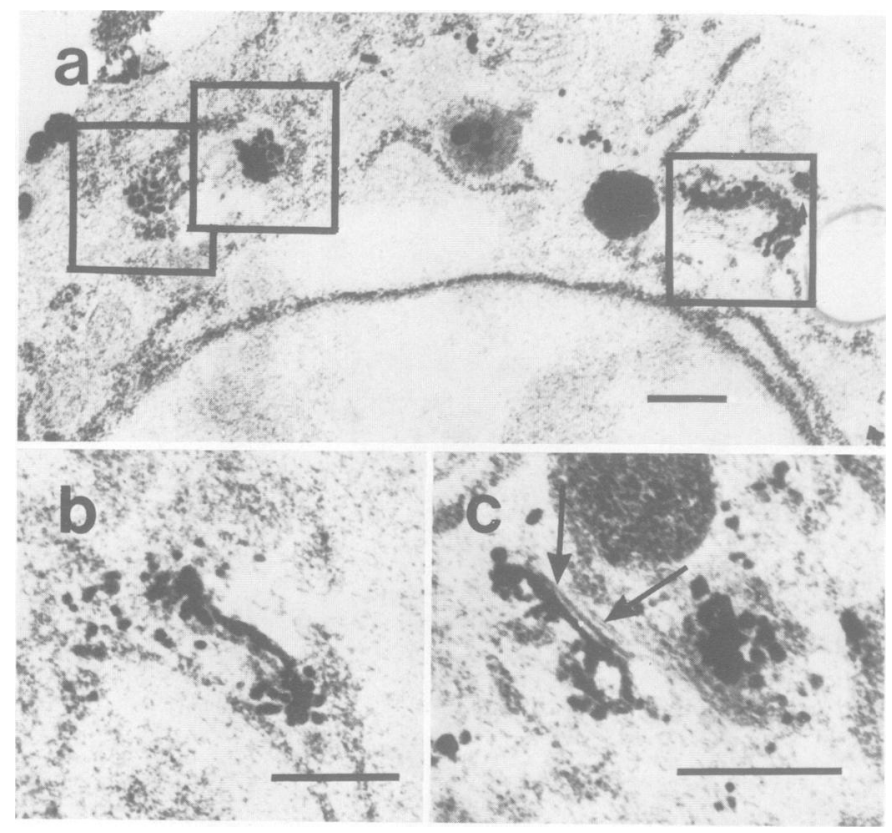

Fig. 6. Reassembling Golgi in late telophase cells. In $0.35-\mu \mathrm{m}$-thick sections, re-forming cis cisternae can be seen in a (right box), b and c (on the left). Typical clusters are also present in a (two boxes on the left) and $c$ (on the right). Cisternae that are negative for osmium and are also reforming are present in c (arrows). Bars $0.5 \mu \mathrm{m}$.
(Table I and Figure 3). Superimposition may make this figure higher but not much, because the cis cisterna, viewed side-on, is narrow, and in order to obscure breaks between discrete apparatus the cis cisternae would have to be interdigitated in the same plane. This is a very unlikely occurrence. Even assuming that superimposition doubles the upper estimate of eight, the number of interphase Golgi apparatus would still be significantly lower than the 100 or more discrete Golgi clusters found in

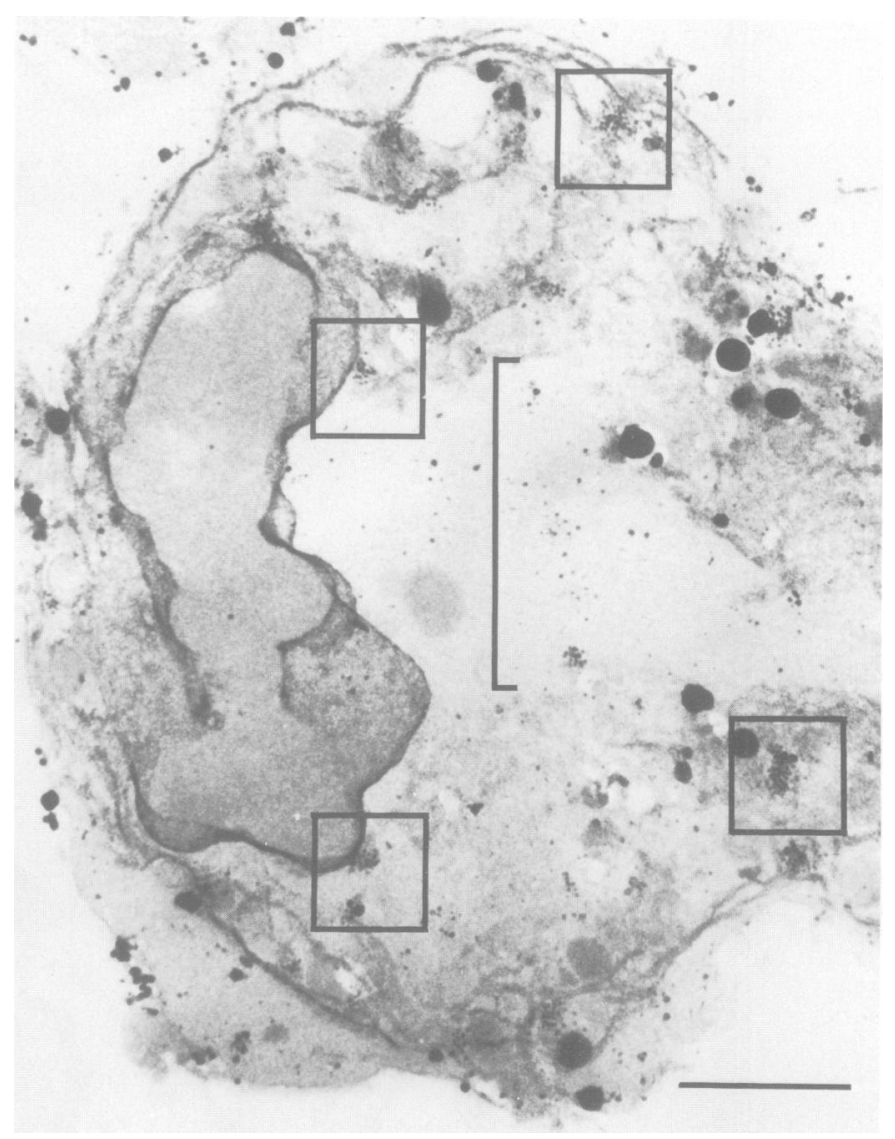

Fig. 7. Golgi clusters in a thick section of a mid-telophase cell. In this $1.5-\mu \mathrm{m}$-thick section $>10$ Golgi clusters (four boxed) are dispersed in the cytoplasm and appear to be excluded from the spindle remnant (bracketed). They also appear on the re-formed nuclear envelope (left boxes). Bar $2 \mu \mathrm{m}$.

Table II. Number of Golgi clusters in mitotic HeLa cells

\begin{tabular}{lll}
\hline Mitotic phase & $\begin{array}{l}\text { Number of Golgi clusters } \\
\text { in each daughter cell }\end{array}$ & $\begin{array}{l}\text { Mean with } \\
\text { confidence } \\
\text { limits }(95 \%)^{\mathrm{a}}\end{array}$ \\
\hline Telophase, mid & 119,114 & $\begin{array}{l}\text { Total number of } \\
\text { Golgi clusters in } \\
\text { each mitotic cell }\end{array}$ \\
Telophase, late & 74,70 & $94(62-126)$ \\
& $83^{\mathrm{b}}$ & \\
& $104^{\mathrm{b}}$ & \\
Metaphase & $\begin{array}{l}\text { Number of Golgi clusters } \\
\text { in each cell }\end{array}$ & $188(\text { est. })^{\mathrm{c}}$ \\
& 188 & $146(56-235)$ \\
\hline
\end{tabular}

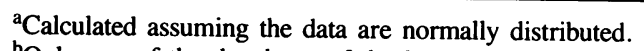

b Only one of the daughters of the late-telophase cells could be counted.

${ }^{\mathrm{c} C o m p a r e d ~ u s i n g ~ t h e ~ M a n n-W h i t n e y ~} U$-test, $n_{1}=3$ and $n_{2}=4$ (one-tailed) $P=0.114$.

est., obtained by doubling the mean. 
each mitotic HeLa cell (Table II). These data show unambiguously that the Golgi apparatus in HeLa cells breaks down during mitosis to give smaller fragments. In other words, the number of dispersed fragments observed during mitosis cannot be explained by the dispersal of multiple Golgi apparatus normally grouped in the centrosomal region of the HeLa cell.

The mechanisms of breakdown is unknown but it may explain why the mitotic Golgi clusters are not miniature versions of the interphase Golgi apparatus. Breakdown must involve membrane fission, and vesiculation of Golgi cisternae might be a prerequisite for fragmentation of the Golgi apparatus as a whole. If this process were to go to completion the endpoint would be the Golgi vesicles found in Golgi clusters. Why the vesicles remain as a cluster and do not disperse completely is unclear but perhaps reassembly during telophase requires a template and the cluster represents the smallest unit which is capable of giving rise to a Golgi stack. In this context it is worth noting that each cluster appears to contain representatives of each of the distinguishable membranes in the interphase Golgi region. Thus they contain both cis (this work) and trans (Lucocq et al., 1987) Golgi markers and the closely apposed ER membrane is derived from the transitional element region.

But why have more than 100 clusters in each mitotic cell? This may be linked to the partitioning mechanism. In the simplest case, an organelle present in multiple copies will be distributed nearly equally between two daughters, providing the organelle is randomly distributed throughout the mitotic cell cytoplasm and providing there is a mechanism for dividing the mother cell into two daughters each of equal size. Mechanisms for the latter are known to exist (Rappaport, 1969) and to give each daughter cell approximately the same volume (Prescott, 1956). This is also true for the HeLa cells we examined as shown in Table III so, providing there are enough Golgi clusters, random partitioning should suffice. So how many is enough? Figure 9 illustrates ran-

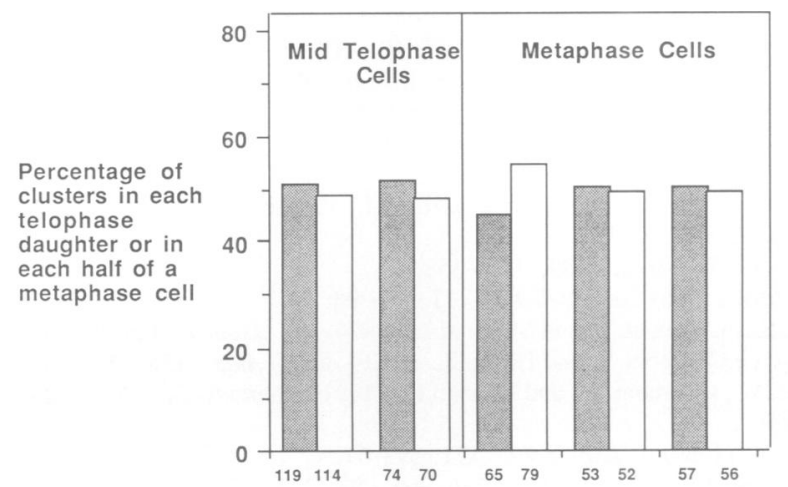

Clusters in one telophase daughter or in one half of metaphase cell Clusters in other telophase daughter or in other half of metaphase cell

Fig. 8. Distribution of Golgi clusters in mitotic HeLa cells. Data from Table II. For metaphase cells, clusters were counted on each side of the equatorial chromosomes. The total is slightly lower than the total numbers shown in Table II because the equatorial chromosomes do not extend to the plasma membrane so that peripheral clusters could not be assigned to one half. The actual number of Golgi clusters is indicated beneath each column.

Table III. Distribution of volume between daughter cells

\begin{tabular}{llll}
\hline Parameter & Mid-telophase cell & One daughter & Other daughter \\
\hline $\begin{array}{l}\text { Volume } \\
\left(\mu \mathrm{m}^{3}\right)\end{array}$ & 2369 & $1174(49.6 \%)$ & $1195(50.4 \%)$ \\
& 2366 & $1275(53.9 \%)$ & $1091(46.1 \%$ \\
\hline
\end{tabular}

dom partitioning for organelles present in $2,10,100$ or 400 copies per mother cell. Clearly, as the number of copies increases, there is an increasing probability that each daughter will receive nearly equal numbers. Mitotic HeLa cells have $>100$ Golgi clusters and at this level $>99.994 \%$ of the daughters will receive between 30 and $70 \%$ of the original complement of organelles. As the number of organelles increases there is also a decreasing probability that a daughter will receive no copies. As shown in Table IV, when there are 100 organelles in each mother cell, there is only one chance in $10^{30}$ that a daughter will receive no

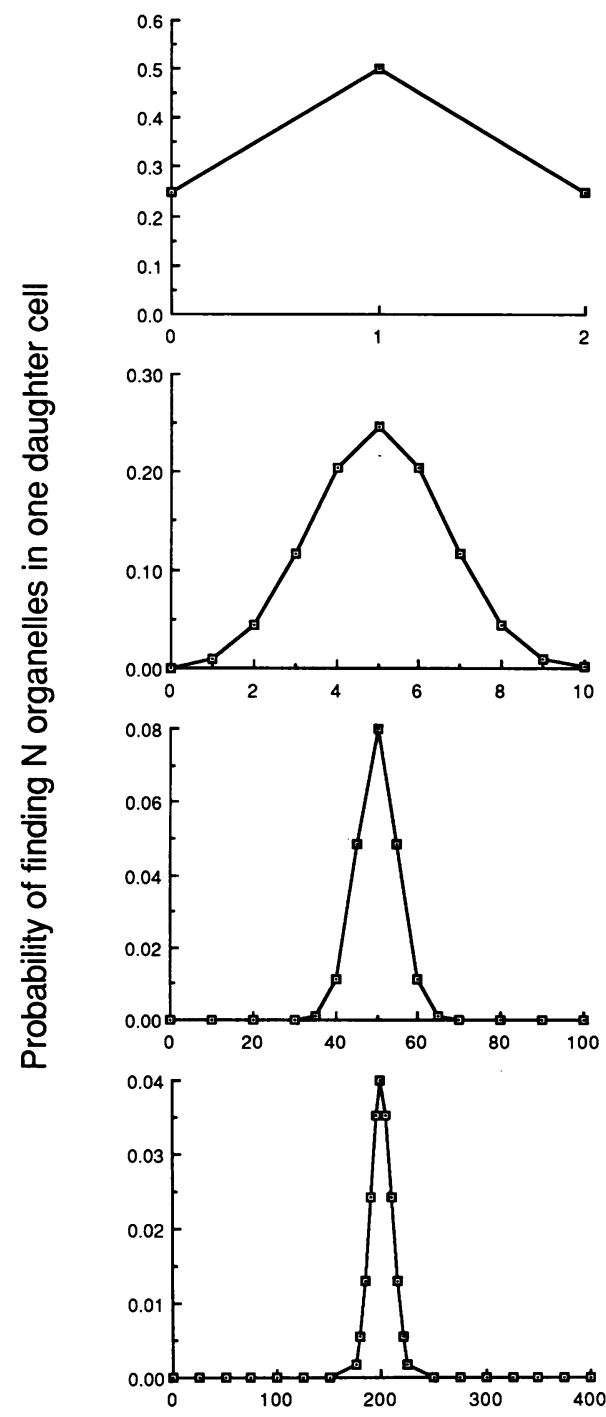

Total number $(\mathrm{N})$ of Organelles

Fig. 9. Random partitioning as a function of organelle number. Calculated from the binomial distribution with $P=0.5$, i.e. that there is an equal probablility of an organelle entering either daughter cell.

Table IV. Probability of daughter cell receiving no organelles

\begin{tabular}{ll}
\hline Number of organelles & $\begin{array}{l}\text { probability } \\
\text { (1 chance in) }\end{array}$ \\
\hline 2 & 4 \\
10 & 1024 \\
100 & $1.2 \times 10^{30}$ \\
400 & $2.6 \times 10^{120}$ \\
\hline
\end{tabular}


organelles. Below 10 organelles there is significant chance. These calculations show that the number of Golgi clusters generated is sufficient for there to be no partitioning mechanism over and above that required to divide the cell into two equal halves. This does not of course mean that there is not a mechanism. The results in Table II and Figure 8 suggest that partitioning might be better than random but whether this is statistically significant will require further work.

The fragmentation and partitioning of the HeLa cell Golgi is the direct consequence of the limited number of copies in the interphase HeLa cell. The major function of the Golgi apparatus is to take the entire output of newly synthesised proteins from the ER and direct these proteins to their final destinations either within or outside the cell (Griffiths and Simons, 1986). There is nothing in this function that demands a limited copy number just as there is still no known function for the Golgi stack (Brands et al., 1985). Nevertheless the structure of the Golgi must be important since the animal cell employs mechanisms which both break it down to clusters and then rebuild it in each daughter cell. Understanding these mechanisms should give us insight into why this structure is so important to the animal cell.

\section{Materials and methods}

Cells

HeLa cells were grown at $37^{\circ} \mathrm{C}$ in minimal essential medium (Flow Labs, Ayrshire, UK) supplemented with $10 \%(\mathrm{v} / \mathrm{v})$ fetal calf serum or new-born calf serum, non-essential amino acids and $100 \mathrm{U} / \mathrm{ml}$ each of penicillin and streptomycin, in an atmosphere of $5 \% \mathrm{CO}_{2} / 95 \%$ air.

Mitotic cells were isolated from subconfluent $(\sim 80 \%)$ monolayer cultures grown in $850-\mathrm{cm}^{2}$ plastic roller bottles rotated at $0.25-0.3$ r.p.m. Debris was removed by rotation at 300 r.p.m. for $3 \mathrm{~min}$ at $37^{\circ} \mathrm{C}$, and after growth for a further $1 \mathrm{~h}$ this high-speed rotation was repeated to shake off the mitotic cells (Klevecz, 1975). These were sedimented at $\sim 2000 \mathrm{~g}$ for $3 \mathrm{~min}$ at $37^{\circ} \mathrm{C}$ and the pellet immediately fixed as described below. Interphase cells were either fixed in situ in the roller bottle or as subconfluent monolayers grown on glass coverslips in plastic Petri dishes.

\section{Electron microscopy}

Osmium tetroxide staining. For prolonged osmication the method of Locke and Huie (1983) as modified by Orci et al. (1984) was used. Fixation in $0.5 \%(w / v)$ glutaraldehyde in $0.1 \mathrm{M}$ cacodylate buffer $\mathrm{pH} 7.4$ for $20 \mathrm{~min}$ at room temperature was followed by three washes in $1 \%(\mathrm{w} / \mathrm{v})$ potassium iodide $(\mathrm{KI})$ in $\mathrm{H}_{2} \mathrm{O}$. The pellets or cells on cover slips were then osmicated in 1 or $2 \%(w / v)$ osmium tetroxide in $1 \% \mathrm{KI}$ at $37^{\circ} \mathrm{C}$ for 2 days and dehydrated in graded ethanols, starting at $70 \%(\mathrm{v} / \mathrm{v})$, and then embedded in epoxy resin (Agar Aids, Essex, UK).

For structural observations, cells were fixed in glutaraldehyde as above and stored in fixative for up to 3 days at $4^{\circ} \mathrm{C}$. Sucrose $(5 \% \mathrm{w} / \mathrm{v})$ was included in some fixation solutions. Following washes in cacodylate buffer, pellets were postfixed in $1 \%$ osmium tetroxide $1.5 \%(\mathrm{w} / \mathrm{v})$ potassium ferrocyanide in $0.1 \mathrm{M}$ cacodylate buffer $\mathrm{pH} 7.4$, for $1 \mathrm{~h}$ at room temperature. Dehydration and embedding were performed as above.

Sections. Thick sections were prepared as described by Favard and Carasso (1973). Briefly, 1- to 2- $\mu \mathrm{m}$-thick sections were cut using glass or diamond knives, alternating several thin sections between each thick section to avoid damage to their upper surface. Sections were collected and mounted on $1 \times 2 \mathrm{~mm}$ slot grids using carbon/formvar films by the method of Galey and Nilsson (1966) as modified by Wells (1974) and observed unstained by transmission electron microscopy at $120 \mathrm{kV}$ in a JEOL $1200 \mathrm{EX}$

Serial thin sections, $\sim 0.2 \mu \mathrm{m}$ thick, of whole mitotic cells were mounted as above and observed unstained at $60 \mathrm{kV}$. No more than one section was lost from each series. Two series of 200 sections obtained from the same block were prepared and three metaphase and four telophase cells (two mid- and two late-telophase) were selected from the middle sections. This ensured that each of these cells would be present in their entirety in the series. Equatorial chromosomes defined metaphase cells whereas the telophase cells used were defined as having an incomplete or complete nuclear envelope and an elongated nuclear profile. Negatives of whole cells were taken at a magnification of $\sim 3000 \times$, calibrated using a line grating replica of 2160 lines $/ \mathrm{mm}$. In one case, that of a mid-telophase cell, eight profiles were photographed at the lower magnification of $2500 \times$ in order to include the whole profile. The number of Golgi clusters on the negatives were counted using a $10 \times$ eyepiece (see results for selection criteria).
Some sections of $0.35 \mu \mathrm{m}$ thickness and thin sections of silver interference colour were mounted on carbon/formvar-coated nickel grids (150 mesh) and stained with uranyl acetate followed by lead citrate, and observed at $60 \mathrm{kV}$.

Quantitation. In order to estimate cell volume, point counting was used. A grid was placed over the profile image and the number of points over all sections was counted. The cell volume is the section thickness multiplied by the product of the number of points and the area associated with each point. Section thickness was estimated by a modification of the method of Gunning and Hardham (1977). This uses the increase in the width of sections mounted on grids when a series of sections is cut from a pyramid trimmed at an known angle to the block face. Simple trigonometry converts the increase in section width for every section cut into thickness per section. No correction for section compression effects was used.

The number of clusters on each side of the chromosomes was noted in metaphase cells by bisecting the mass of aligned chromosomal profiles. Clusters in telophase were counted on either side of the shortest line that spanned the cleavage furrow. Thiamine pyrophosphatase. The thiamine pyrophosphatase (TPPase) reaction and controls were performed as described previously (Lucocq et al., 1987).

\section{Acknowlegements}

We would like to thank Mr K.Leask for technical assistance. This research was supported by grant number SP 1755 from the Cancer Research Campaign.

\section{References}

Birky,C.W. (1983) Int. Rev. Cytol., 15, 49-89.

Brands, R., Snider,M.D., Hino,Y., Park,S.S., Gelboin,H.V. and Rothman,J.E. (1985) J. Cell Biol., 101, 1724-1732.

Burke,B., Griffiths,G., Reggio,H., Louvard,D. and Warren,G. (1982) EMBO $J ., 1,1621-1628$.

Favard,P. and Carasso,N. (1973) J. Microsc., 97, 59-81.

Featherstone,C., Griffiths,G. and Warren,G. (1985) J. Cell Biol., 101, 2036-2046.

Friend,D.S. (1969) J. Cell Biol., 41, 269-279.

Friend,D.S. and Murray,M.J. (1965) Am. J. Anat., 117, 135-150.

Galey,F. and Nilsson,S.E.G. (1966) J. Ultrastruct. Res., 14, 405-410.

Griffiths,G. and Simons,K. (1986) Science, 234, 438-443.

Gunning,B.E.S. and Hardham,A.R. (1977) J. Microsc., 109, 337-340.

Hiller,G. and Weber,K. (1982) Exp. Cell. Res., 142, 85-94.

Klevecz,R.R. (1975) Methods Cell Biol., 10, 157-173.

Locke,M. and Huie,P. (1983) J. Histochem. Cytochem., 31, 1019-1032.

Louvard,D., Reggio,H. and Warren,G. (1982) J. Cell Biol., 92, 92-107.

Lucocq,J.M., Pryde,J., Berger,E. and Warren,G. (1987) J. Cell Biol., 104, 865-874.

Ludford,R.J. (1924) Proc. R. Soc. B, 97, 50-60.

Mann,H.B. and Whitney,D.R. (1947) Ann. Math. Statist., 18, 50-60.

Maul,G.G. and Brinkley,B.R. (1970) Cancer Res., 30, 2326-2335.

Novikoff,P.M., Novikoff,A.B., Quintana,N. and Hauw,J.-J. (1971) J. Cell Biol., 50, 859-886.

Orci,L., Halban,P., Amherdt,M., Ravazzola,M., Vassali,J.-D. and Perrelet,A. (1984) Cell, 39, 39-47.

Palade,G. (1975) Science, 189, 347-358.

Prescott,D.M. (1956) Exp. Cell Res., 11, 86-98.

Rambourg,A., Clermont,Y. and Marraud,A. (1974) Am. J. Anat., 140, 27-46.

Rambourg,A., Clermont,Y. and Hermo,L. (1979) Am. J. Anat., 154, 455-476.

Rambourg,A., Clermont,Y. and Hermo,L. (1981) Methods Cell Biol., 23, 155-166.

Rappaport,R. (1969) J. Exp. Zool., 171, 59-67.

Roth,J. and Berger,E.G. (1982) J. Cell Biol., 93, 223-229.

Warren,G. (1985) Trends Biol. Sci., 10, 439-443.

Wells,B. (1974) Micron, 5, 79-81.

Wilson,E.B. (1925) The Cell in Development and Heredity. MacMillan, New York.

Zeligs,J.D. and Wollman,S.H. (1979) J. Ultrastruct. Res., 66, 53-77.

Zorn,G.A. Lucas,J.J. and Kates,J.R. (1979) Cell, 18, 659-672.

Received on June 16, 1987; revised on August 3, 1987 